\title{
Our New Journal of CSWB: Relevance Matters
}

\author{
Dave Malloy*
}

Our world is changing rapidly and our concerns for community safety have never been more acute. While we in Canada struggle with our own tragedies of missing and murdered indigenous woman, unacceptable incarceration rates, and violence within our indigenous communities, we witness seemingly unprecedented racial unrest south of the border. International and domestic terror seems to magnify our thoughts about safety and the future of our children. Fear and suspicion brought on by sensational media and outrageous political agendas exacerbate the paranoia.

From Aristotle's ethical and political theories to Canada's Charter of Rights and Freedoms, there is a fundamental expectation that our communities should allow each and every one of us to flourish. But, without safety in our homes, on our streets, at our soccer pitches and shopping malls, and in our places of work, it becomes impossible to develop our full capacities in the arts, sciences, commerce, and leisure, or our political awareness and action. How do we make sense of it all?

We of course have access to information from a variety of sources-from the CBC to Fox, from The Globe $\mathcal{E}$ Mail and The Guardian to The National Enquirer. Yet often the information we read is subtly or outrageously biased, inaccurate or simply entertainment. At the other extreme we have academic papers written in esoteric journals for limited audiences using jargon unknown to the layperson. These academic papers are often problematic because the information they contain may not be accessible to all readers and, sadly, they can become as irrelevant to the public discourse as the biased pseudo press.

So, how do we navigate through the morass of fear mongering and Internet falsehood, and the impenetrable academic discourse, in order to make clear assessments of fact and sound decisions about not only social policy and societal values, but also how to live our lives in this chaotic world?

As founding members of the Community Safety Knowledge Alliance (CSKA), The University of Regina believes wholeheartedly that the Journal of Community Safety $\mathcal{E}$ WellBeing can act as a key source of information for its readership to better understand the pressures on community safety and professional practice. The articles published in the Journal are of the highest calibre; each is screened through a rigorous peerreview process that ensures the highest quality of method, analysis, discussion, and relevancy. While the former three are givens in all good scholarly journals, it is the latter that is key for the CSKA-relevance. The information contained within needs to be published; needs to be read; needs to be understood; and needs to be functional, practical, and relevant. This is the Journal's mandate.

The Journal of CSWB provides us with a germane resource to better understand our world and how we can live and flourish in our times. It is written by both leading academics and practitioners, with the mandate that the articles must be both academically rigorous and functionally relevant to practitioners.

Our hope is that this Journal, as it grows and evolves, will make a difference in your professional practice, and may help guide the decisions you make to keep our communities safe in this ever-changing world.

\section{CONFLICT OF INTEREST DISCLOSURES}

The author is a member of the oversight board for the Journal of Community Safety and Well-Being.

\section{AUTHOR AFFILIATIONS}

*Vice President Research, University of Regina. 